\title{
Complete disappearance of intra-bullous component in a patient with infectious bullae
}

\author{
Kengo NISHINO(ID) \\ Hiroaki SATOH(ID)
}

Division of Respiratory Medicine, Mito Medical Center, University of Tsukuba, Mito, Japan

Tsukuba Üniversitesi Mito Tıp Merkezi, Solunum Tıbbı Bölümü, Mito, Japonya
Cite this article as: Nishino K, Satoh H. Complete disappearance of intra-bullous component in a patient with infectious bullae. Tuberk Toraks 2021;69(2):291-292.

\section{Yazışma Adresi (Address for Correspondence)}

\section{Dr. Hiroaki SATOH}

Division of Respiratory Medicine,

Mito Medical Center, University of Tsukuba,

Miya-machi 3-2-7,

Ibaraki, 310-0015, MITO - JAPAN

e-mail: hirosato@md.tsukuba.ac.jp

CCopyright 2021 by Tuberculosis and Thorax.

Available on-line at www.tuberktoraks.org.com
To the Editor,

A 73-year-old male presented to our hospital with a two-week history of bloody sputum. At the age of 66 years, the patient was diagnosed having severe chronic obstructive pulmonary diseases, and respiratory function test performed two years before revealed forced expiratory volume in one second $18 \%$ predicted. Chest CT showed pulmonary bullae with intra-bullous component. Extensive thickening of the walls of the bullae and bullae with air-fluid level in the lower lobe were also observed in chest CT scan. As serum aspergillus antigen was positive, suggesting Aspergillus infection, administration of liposomal-amphotericin B (L-AMB), an antifungal drug, was started. Soon after the administration of L-AMB (2.5 $\mathrm{mg} / \mathrm{kg} /$ day) was started, bloody sputum improved. L-AMB was administered for 21 days, and was discontinued after confirming normalization of the inflammatory response. Since then, the patient has not received antibacterial agents, including antifungal agents. Chest CT taken 12 months after the termination of treatment confirmed shrinkage of the intra-bullous component (Figure 1-B). The component was completely disappeared on CT scan taken at 36 months after the after the termination of treatment (Figure 1-C).

As the walls of bulla is presumed to have poor blood flow, therefore, intra-bullous components are not easily absorbed, even if there is a possibility of being drained into the respiratory tract. In 

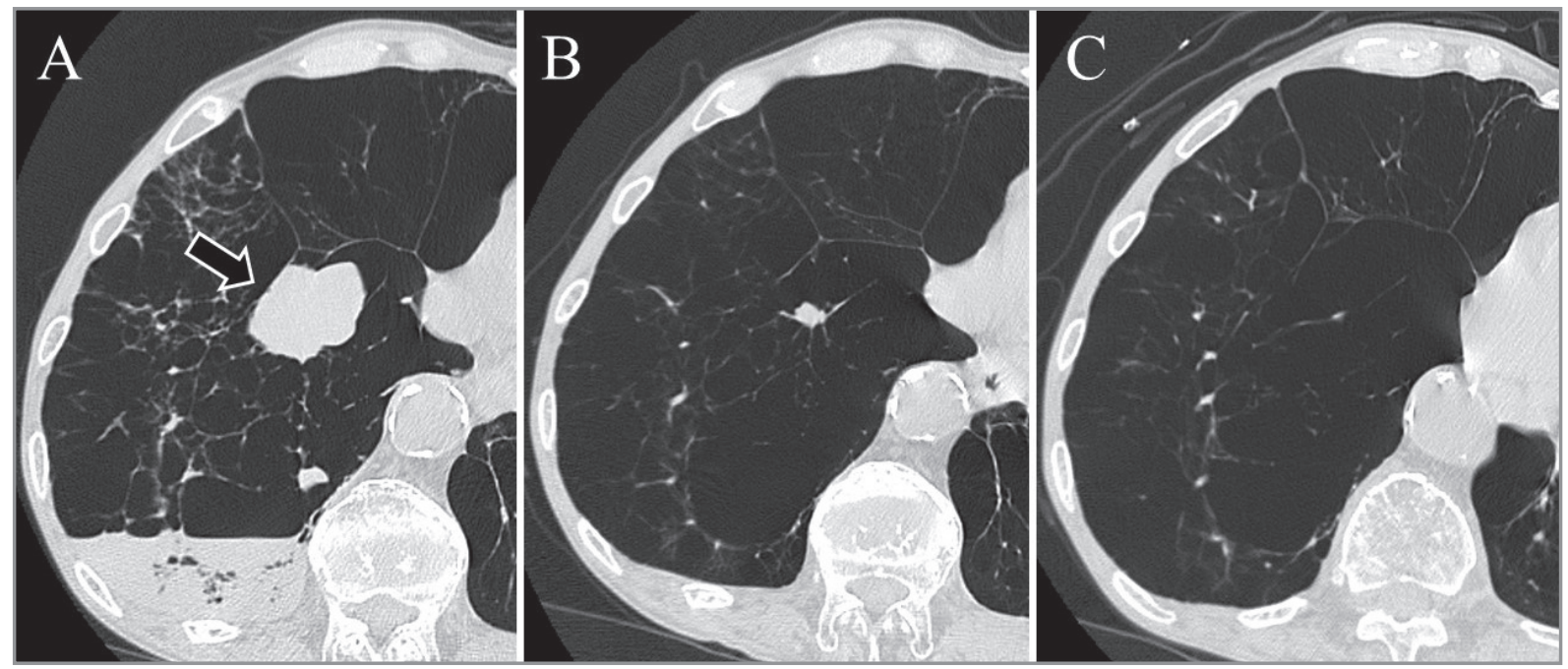

Figure 1. A. Chest CT showed pulmonary bullae with intra-bullous component (arrow). Extensive thickening of the walls of the bullae and bullae with air-fluid level in the lower lobe were also observed, B. Chest CT taken 12 months after the termination of treatment confirmed shrinkage of the intra-bullous component, $\mathbf{C}$. The component completely disappeared in CT scan taken at 36 months after the after the termination of treatment.

this patient, respiratory condition was poor, so bronchoscopic sampling was not performed from inside the pulmonary bullae. Therefore, it was not possible to clarify the component that was present in the bullae. Component to be differentiated was fungus ball, blood retention, and airway secretions. As a fungus ball, it did not appear to be a typical air crescent sign (meniscus sign) $(1,2)$ on chest CT. Since his chief complaint was bloody sputum, it could be blood retention (3). Some bullae with air-fluid level were present in the same lobe at the same time. On the other hand, it was interesting that this bulla had no air-fluid level. This component might be a fungus ball or intra-bullous storage material such as blood and airway secretions. Although rare, we showed a case with disappearance of intra-bullous component over the years.

\section{REFERENCES}

1. Sevilha JB, Rodrigues RS, Barreto MM, Zanetti G, Hochhegger B, Marchiori E. Infectious and non-infectious diseases causing the air crescent sign: A state-of-the-art review. Lung 2018; 196(1): 1-10.

2. Algın O, Gökalp G, Topal U. Signs in chest imaging. Diagn Interv Radiol 201; 17(1): 18-29.

3. Nakamura H, Takamori S, Miwa K, Fukunaga M, Maeshiro $K$, Matsuo $T$, et al. Rapid-growth lung cancer associated with a pulmonary giant bulla: a case report. Kurume Med J 2003; 50(3-4): 147-50. 